\title{
Hybrid Inorganic-Organic Perovskite Glasses
}

Bikash Kumar Shaw ${ }^{1}$, Ashlea R. Hughes ${ }^{2}$, Maxime Ducamp ${ }^{3}$, David A. Keen ${ }^{4}$, Francois-Xavier Coudert ${ }^{3}$, Frédéric Blanc ${ }^{2,5}$ and Thomas D. Bennett ${ }^{* 1}$

${ }^{1}$ Department of Materials Science and Metallurgy, University of Cambridge, CB3 OFS, UK.

${ }^{2}$ Department of Chemistry, University of Liverpool, Crown Street, Liverpool L69 7ZD, UK.

${ }^{3}$ Chimie ParisTech, PSL University, CNRS, Institut de Recherche de Chimie Paris, 75005 Paris, France.

${ }^{4}$ ISIS Facility, Rutherford Appleton Laboratory, Harwell Campus, Didcot, Oxon OX11 OQX, UK.

${ }^{5}$ Stephenson Institute for Renewable Energy, University of Liverpool, Crown Street, Liverpool L69 7ZD, UK.

Email: tdb35@cam.ac.uk

Hybrid perovskites occupy a prominent position within solid-state materials chemistry due to their (e.g.) ionic transport, ferroelectric and multiferroic properties. Here we show that a series of $[\operatorname{TPrA}]\left[\mathrm{M}(\mathrm{Dca})_{3}\right]$ perovskites $(\operatorname{TPr} \mathrm{A}=$ tetrapropylammonium cation; $\mathrm{Dca}=$ dicyanamide anion; $\mathrm{M}=\mathrm{Mn}, \mathrm{Fe}, \mathrm{Co})$ melt below $300{ }^{\circ} \mathrm{C}$. A combined experimental-computational approach reveal the melting mechanism, and demonstrates that the hybrid perovskites form glasses upon melt quenching which largely retain the inorganic-organic bonding of the crystalline phase. The very low thermal conductivities of these glasses $\left(\sim 0.2 \mathrm{~W} \mathrm{~m}^{-1} \mathrm{~K}^{-1}\right)$, moderate electrical conductivities $\left(10^{-2}-10^{-4} \mathrm{~S} \mathrm{~m}^{-1}\right)$ and thermo-mechanical properties reminiscent of polymeric materials identify them as a new family of functional glass-formers. 


\section{Introduction}

$A B X_{3}$ hybrid perovskites $(A=$ organic cation, $B=$ metal ion, $X=$ bridging ligand $)$ occupy a prominent position within solid state chemistry and materials science due to versatile utility in e.g. ionic transport, ferroelectric, luminescent and multiferroic applications ${ }^{1}$. Hybrid lead iodide perovskites $\left(\mathrm{APbl}_{3}\right)$ in particular have been extensively targeted for their potential in photovoltaic devices ${ }^{2,3}$. More recent strategies concentrate on leadfree functional perovskite materials, in which the halide linker is replaced by flexible multidentate organic bridging units such as formate [ $\left.\mathrm{HCOO}^{-}\right]$, hypophosphite $\left[\mathrm{H}_{2} \mathrm{POO}-\right.$ ] and dicyanamide [Dca, $\left.\left.\mathrm{C}_{2} \mathrm{~N}_{3}^{-}\right]\right)^{4,5}$. The presence of extended inorganic-organic connectivity means that a selection of hybrid perovskite structures meet the given definition of a metal-organic framework (MOF) ${ }^{6}$. Indeed, many of the 80,000 reported MOFs adopt perovskite architectures, though these tend not to be the highly porous structures known for their ability to selectively adsorb guest molecules ${ }^{7}$. Instead, they are more dense materials, which exhibit interesting magnetic and electronic properties ${ }^{8}$.

The crystalline state however dominates both materials families. Targeted order in MOF structures has been a primary focus of the field for decades, whilst the array of interesting physical behavior reported in hybrid perovskite structures is typically associated with transitions from one crystalline state to another. Solid-liquid transitions have however started to be reported in $\mathrm{MOFs}^{9}$. For example, the melt-quenching of several structures results in the formation of a new category of glasses, which are structurally similar to silica glass, yet contain linked inorganic and organic components ${ }^{10}$. Accordingly, the mechanical and optical properties of these 'hybrid' glasses are of great interest.

In this report, we take advantage of the known lability of the chemistry common to both hybrid perovskite and MOF families ${ }^{11}$, and extend the phenomenon of melting to the $\mathrm{ABX}_{3}$ perovskite family. The [TPrA][M(Dca) $)_{3}$ (TPrA = tetrapropylammonium cation, $\mathrm{M}$ $=\mathrm{Mn}, \mathrm{Fe}, \mathrm{Co}$ ) family were selected for study due to the multiple possible coordination modes possible for the Dca ligand, which bridge transition metal cations through the $N$ atom in $\mu 1,5$ end-to-end fashion. TPrA cations are situated in the pseudocubooctahedral cavities, resulting in multifunctional 3D perovskite architectures (Fig. 1a). $\mathrm{Fe}(\mathrm{II}), \mathrm{Ni}(\mathrm{II})$ and $\mathrm{Co}(\mathrm{II})$ analogues for example each exhibit three first order 
dielectric transitions, arising from displacement of both TPrA and Dca ${ }^{12}$. The Mn(II) analogue shows type-I multiferroism ${ }^{4}$, due to coupling between antiferroelectric (AFE) and antiferromagnetic (AFM) order. A high sensitivity to both temperature and applied external pressure facilitates a giant caloric effect of $37.0 \mathrm{~J} \mathrm{~kg}^{-1} \mathrm{~K}^{-113}$. This occurs under very low applied pressures $(P<7 \mathrm{MPa})$, just above room temperature, with a calculated barocaloric coefficient ${ }^{13}\left(\partial \mathrm{T}_{\mathrm{t}} / \partial \mathrm{P}\right)$ of $23.1 \mathrm{~K} \mathrm{kbar}^{-1}$.

In this work, we show that these structures melt at low temperatures, and that the liquids formed can be quenched into hybrid glasses that are structurally dissimilar to existing MOF and coordination polymer glasses. We elucidate the melting mechanism, provide structural characterization of the glass phase and demonstrate exciting thermal and electrical conductivities in this new category of functional glasses.

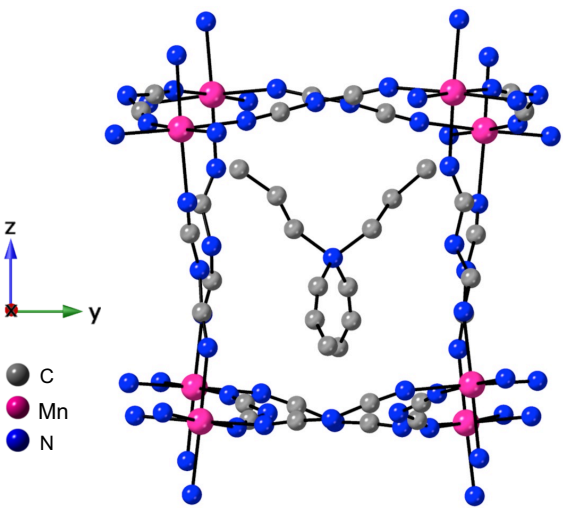

C

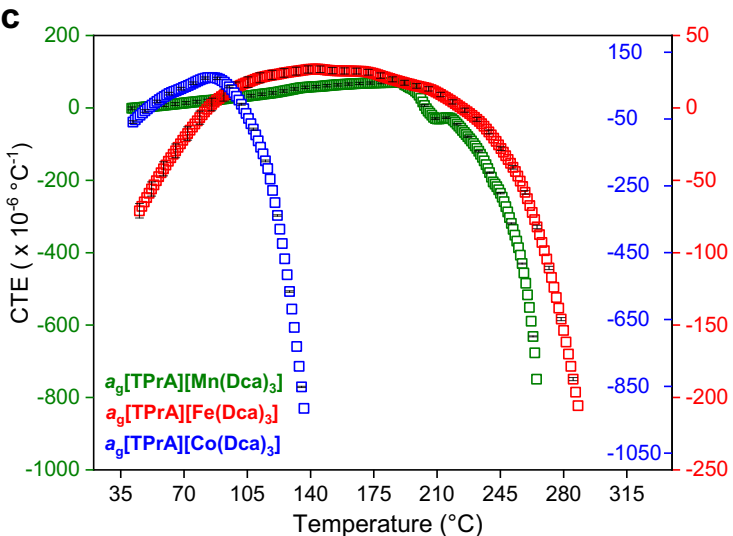

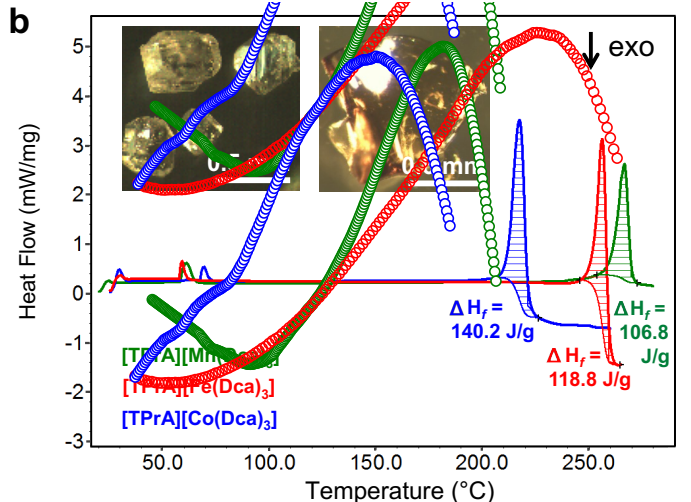

d

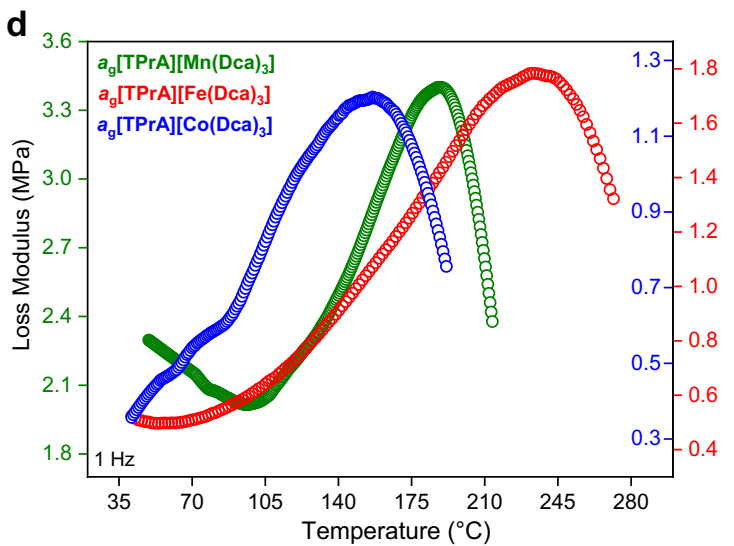

Figure 1. Glass formation from hybrid perovskites. a, Unit cell structure of [TPrA][Mn(Dca $\left.)_{3}\right]$ at room temperature ${ }^{4}$. Pink: Mn; Grey: C; Blue: N; H atoms omitted for clarity. b. Change in heat flow with increase in temperature for $[\operatorname{TPr} A]\left[M(D c a)_{3}\right]$ samples. Values for the enthalpy of fusion $\left(\Delta H_{f}\right)$ were extracted from the shaded sigmoidal areas. Inset. Optical images of $[\operatorname{TPrA}]\left[\mathrm{Mn}(\mathrm{Dca})_{3}\right]$ before heating (left) and after melt-quenching (right). c, Variation of the coefficient of linear thermal expansion ( $\alpha$ ) are shown with temperature for $a_{g}[\operatorname{TPA}]\left[\mathrm{M}(\mathrm{Dca})_{3}\right]$. Sudden drops in a indicate the $T_{\mathrm{f}}$ point in each case. Error bars in black. $\mathbf{d}$, Variation of the loss modulus as a function of temperature of $a_{g}[\operatorname{TPA} A]\left[M(D c a)_{3}\right]$ at $1 \mathrm{~Hz}$. Glass transition temperatures $\left(T_{\mathrm{g}}\right)$ are ascertained from their peak values (Table 1). 


\section{$\underline{\text { Results }}$}

\section{Glass Formation and Thermal Properties}

Single crystals of $[\operatorname{TPr}]\left[\mathrm{M}(\mathrm{Dca})_{3}\right](\mathrm{M}=\mathrm{Mn}, \mathrm{Fe}, \mathrm{Co})$ were obtained by solvent layering, following previously reported procedures ${ }^{4}$ (Supplementary methods, Supplementary Fig. 1). Thermogravimetric analysis revealed decomposition temperatures $\left(T_{\mathrm{d}}\right)$ of $281^{\circ} \mathrm{C}, 271^{\circ} \mathrm{C}$ and $266{ }^{\circ} \mathrm{C}$ for the $\mathrm{Mn}$, Fe and Co analogues respectively (Supplementary Fig. 2). Differential scanning calorimetry (DSC) was carried out on each sample, and identified sharp endotherms at temperatures far in excess of the reported solid-solid polymorphic phase transitions associated with TPrA cation reorientation ${ }^{4,12}$. The temperatures of these features, indicative of an unreported phase transition, correspond to melting $\left(T_{\mathrm{m}}\right)$ at $271^{\circ} \mathrm{C}, 263^{\circ} \mathrm{C}$ and $226{ }^{\circ} \mathrm{C}$ for the $\mathrm{Mn}, \mathrm{Fe}$ and $\mathrm{Co}$ analogues (Fig. 1b). Liquid-like behaviour was evident from the physical appearance of samples upon cooling from the melt (Supplementary Fig. 3), which were X-ray amorphous (Supplementary Fig. 4) and contained striations induced by thermal stress (Supplementary Fig. 5). The glasses, in keeping with existing nomenclature on hybrid glasses, are termed $a_{g}[\operatorname{TPr}]\left[M(D c a)_{3}\right]\left(a_{g}\right.$ : melt quenched glass).

Reheating of the three $a_{g}[\operatorname{TPr} A]\left[M(D c a)_{3}\right]$ samples in a subsequent DSC experiment yielded smooth but weak changes in the heat flow, indicative of glass transitions $\left(T_{\mathrm{g}}\right)$, at temperatures of $218^{\circ} \mathrm{C}$ and $222^{\circ} \mathrm{C}$ for $a_{g}[\operatorname{TPrA}]\left[\mathrm{Mn}(\mathrm{Dca})_{3}\right]$ and $a_{g}[\operatorname{TPrA}]\left[\mathrm{Fe}(\mathrm{Dca})_{3}\right]$. One could not be identified for $a_{g}[\operatorname{TPrA}]\left[\mathrm{Co}(\mathrm{Dca})_{3}\right]$ (Supplementary Fig. 6, Table 1). Minimal gravimetric mass loss was detected on heating of the glasses from room temperature to their respective glass transitions (Supplementary Fig. 7).

Thermomechanical analysis (TMA) was performed on the $a_{g}[\operatorname{TPrA}]\left[M(D c a)_{3}\right]$ samples, and the resultant dilatometric softening temperatures $\left(T_{\mathrm{f}}\right)$, i.e. where the solid glass began to transform into a softer state, used to corroborate the values of $T_{\mathrm{g}}$ extracted from DSC measurements (Fig. 1c, Supplementary Fig. 8). Frequency-dependent dynamic mechanical analysis (DMA), a more sensitive method of obtaining the glass transition, was performed and able to identify values in all three cases. $T_{\mathrm{g}}$ values of $190^{\circ} \mathrm{C}, 229^{\circ} \mathrm{C}$ and $151^{\circ} \mathrm{C}$ were obtained for $a_{g}[\operatorname{TPrA}]\left[\mathrm{Mn}(\mathrm{Dca})_{3}\right], a_{g}[\operatorname{TPrA}]\left[\mathrm{Fe}(\mathrm{Dca})_{3}\right]$, and $a_{g}[\operatorname{TPr}]\left[\mathrm{Co}(\mathrm{Dca})_{3}\right]$ from the maximum value of the loss modulus (Fig. 1d, 
Supplementary Fig. 9 $)^{14}$, which agree with those obtained from TMA and DSC measurements (Table 1).

The shift in $T_{\mathrm{g}}$ to higher temperature with increasing applied frequency was used to calculate activation energies $\left(E_{\mathrm{a}}\right)$ associated with $T_{\mathrm{g}}$ using the Arrhenius equation (1) (Table 1, Supplementary Fig. 10, Supplementary Table 1).

$$
\log \frac{f_{1}}{f_{2}}=\frac{E_{\mathrm{a}}}{R}\left(\frac{1}{T_{\mathrm{g}_{2}}}-\frac{1}{T_{\mathrm{g}_{1}}}\right)
$$

Where $f_{1}, f_{2}=$ applied frequencies, $T_{\mathrm{g}_{1}}, T_{\mathrm{g}_{2}}=$ glass transitions at the applied frequencies, $R=$ ideal gas constant.

Table 1. Physical properties of solid-liquid transitions in hybrid perovskites. ${ }^{a}$

\begin{tabular}{|c|c|c|c|c|c|c|c|}
\hline Samples & $\begin{array}{c}T_{m} \\
\left({ }^{\circ} \mathrm{C}\right)\end{array}$ & $\begin{array}{c}\Delta H_{\mathrm{f}} \\
\left(\mathrm{kJ} \mathrm{mol}^{-1}\right)\end{array}$ & $\begin{array}{c}T_{g}-\text { DSC } \\
\left({ }^{\circ} \mathrm{C}\right)\end{array}$ & $\begin{array}{l}\text { TMA } \\
\left({ }^{\circ} \mathrm{C}\right)\end{array}$ & $\begin{array}{c}\text { DMA - Onset } \\
\text { of Storage } \\
\text { Modulus }\left({ }^{\circ} \mathrm{C}\right)\end{array}$ & $\begin{array}{c}\text { DMA - Peak } \\
\text { of Loss } \\
\text { Modulus }\left({ }^{\circ} \mathrm{C}\right)\end{array}$ & $\begin{array}{c}E_{\mathrm{a}} \\
\left(\mathrm{kJ} \mathrm{mol}^{-1}\right)\end{array}$ \\
\hline$[\mathrm{TPrA}]\left[\mathrm{Mn}(\mathrm{Dca})_{3}\right]$ & 271 & 46.8 & 218 & 202 & 185 & 190 & 19.9 \\
\hline$[\mathrm{TPrA}]\left[\mathrm{Fe}(\mathrm{Dca})_{3}\right]$ & 263 & 50.1 & 222 & 220 & 216 & 229 & 24.9 \\
\hline$[\mathrm{TPrA}]\left[\mathrm{Co}(\mathrm{Dca})_{3}\right]$ & 226 & 62.5 & $-b$ & 102 & 143 & 151 & 20.5 \\
\hline
\end{tabular}

a Errors associated with determination of $T_{\mathrm{g}}$ are typically up to $2{ }^{\circ} \mathrm{C}$ from DSC and $10-20{ }^{\circ} \mathrm{C}$ from DMA ${ }^{15}$. ${ }^{\mathrm{b}}$ Not experimentally observed. This is consistent with the reduced sensitivity of DSC compared to DMA in observing the glass transition ${ }^{15}$.

\section{Delineating Decoordination, Rearrangement and Reduction Processes}

Structural insights into the glasses were sought using several spectroscopic methods. ${ }^{13} \mathrm{C}$ Nuclear Magnetic Resonance (NMR) spectra of [TPrA][Mn(Dca $\left.)_{3}\right]$, $[\operatorname{TPrA}]\left[\mathrm{Fe}(\mathrm{Dca})_{3}\right]$ and $[\mathrm{TPrA}]\left[\mathrm{Co}(\mathrm{Dca})_{3}\right]$ before and after melt-quenching were obtained using an optimised approach for paramagnetic materials (Fig. 2a, Supplementary Figs. 11-13 $)^{16-18}$. Spectra of $[\operatorname{TPr}]\left[\mathrm{Fe}(\mathrm{Dca})_{3}\right]$ and $[\operatorname{TPr}]\left[\mathrm{Co}(\mathrm{Dca})_{3}\right]$ contain one resonance in the 200 to $-100 \mathrm{ppm}$ region per type of carbon in the TPrA cation and two (or more) poorly resolved resonances around $3900 \mathrm{ppm}$ for the NCN carbon of the Dca anions (see below for spectral assignment and Supplementary Figs. 14, 15). In contrast, in crystalline [TPrA] $\left.\mathrm{Mn}(\mathrm{Dca})_{3}\right]$ where the NMR lines are much narrower, resonances for each type of carbons in the TPrA and Dca ions (e.g. the NCN resonance appears as two resolved shifts of 7 and $3 \mathrm{ppm}$ in a 2:1 ratio) can be observed (Supplementary Fig. 16). These observations are consistent with the phases expected based on previous reports of phase transitions in the family. 
Specifically, they support the existence of one TPrA cation and two Dca anions in the asymmetric unit cell within the orthorhombic Ibam (centrosymmetric) space group of $[\operatorname{TPrA}]\left[\mathrm{Fe}(\mathrm{Dca})_{3}\right]$ and $[\mathrm{TPrA}]\left[\mathrm{Co}(\mathrm{Dca})_{3}\right]^{12}$, and the presence of three independent ions in the tetragonal space group $P-42{ }_{1} C$ of $[\operatorname{TPrA}]\left[\mathrm{Mn}(\mathrm{Dca})_{3}\right]$ below $60{ }^{\circ} \mathrm{C}^{4}$. The spectra were assigned based on known chemical shift values for TPrA in diamagnetic systems ${ }^{19}$, spatial proximity to the metal centres and ${ }^{13} \mathrm{C}$-edited experiment using ${ }^{1} \mathrm{H}$ ${ }^{13} \mathrm{C}$ TEDOR ${ }^{18,20}$ (transferred echo double resonance) experiments that filter out any non-protonated carbons (Supplementary Figs. 11-13, Methods). The absence of ${ }^{13} \mathrm{C}$ signal at ca. 3900 ppm in both [TPrA][Fe(Dca $\left.)_{3}\right]$ and [TPrA] $\left[\mathrm{Co}(\mathrm{Dca})_{3}\right]$ TEDOR spectra strongly supports its assignment to the NCN carbon of the Dca anions which contains the only quaternary carbon amongst both TPrA and Dca ions. It is therefore postulated that the very large paramagnetic shifts observed in Dca result from its $\mu 1,5$ bonding mode to two metal centres (Fig. 1a). Notably, the NCN carbon within the $[\operatorname{TPrA}]\left[\mathrm{Fe}(\mathrm{Dca})_{3}\right]$ and $[\operatorname{TPrA}]\left[\mathrm{Co}(\mathrm{Dca})_{3}\right]$ materials appears at a very similar chemical shift, which is also seen elsewhere in literature ${ }^{21}$. The ${ }^{13} \mathrm{C}$ shifts of the TPrA cation are significantly less affected due to the greater distance of this species from the metal centres (Fig. 1a), whilst the different chemical shift of the Dca ligand in crystalline [TPrA][Mn(Dca) $)_{3}$ (ca. 5 ppm, Fig. 2a, Supplementary Fig. 11 and Supplementary Table 2) is ascribed to the difference in magnetic susceptibility of $\mathrm{Mn}^{2+}$, in comparison to $\mathrm{Fe}^{2+}$ and $\mathrm{Co}^{2+}$. This yields smaller anisotropic bulk magnetic susceptibility broadening in the former, consistent with ${ }^{7} \mathrm{Li} \mathrm{MAS} N \mathrm{NMR}$ of $\mathrm{LiMPO}_{4}, \mathrm{M}=\mathrm{Mn}, \mathrm{Fe}$, Co ${ }^{16,21}$.

Comparison of the spectra of crystalline and glass samples (Fig. 2a, Supplementary Figs. 11-13) shows similar chemical shifts in the TPrA region, suggesting that the ' $A$ ' site cation remains mostly intact during the melt-quenching process. No resonances for Dca are observed in their paramagnetic NMR regions for any of the quenched glasses due to a likely decrease in the $T_{2}$ ' upon vitrification and hence, an increase in paramagnetic broadening of the glasses. 


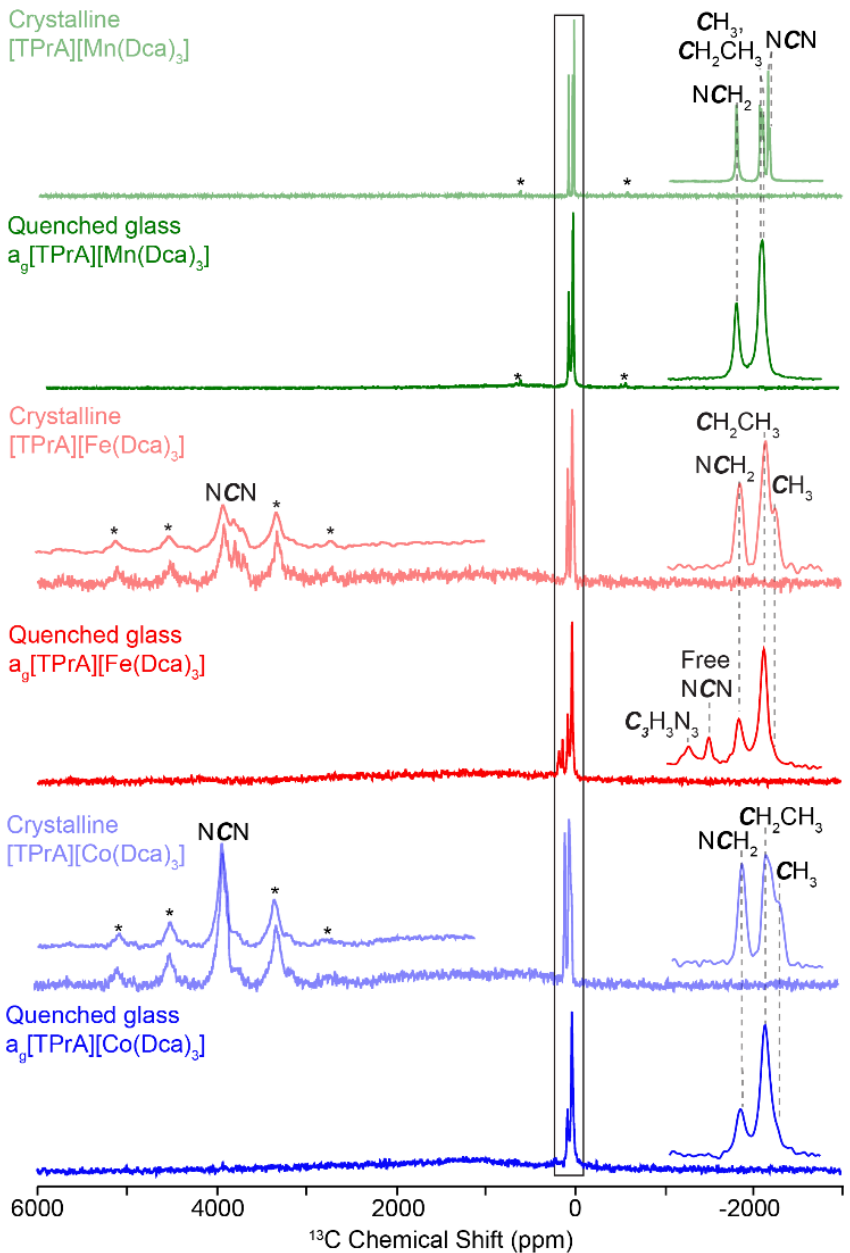

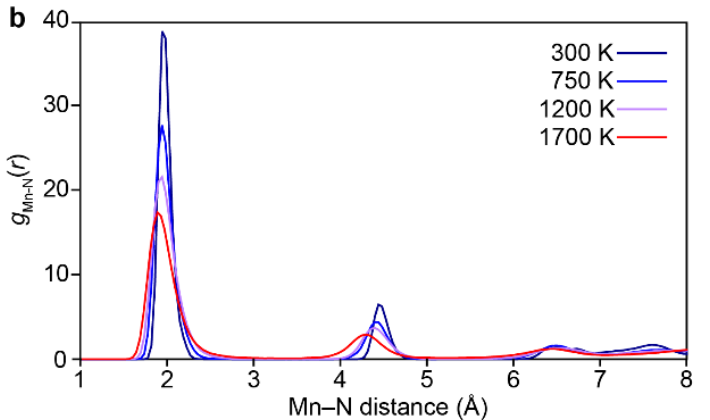
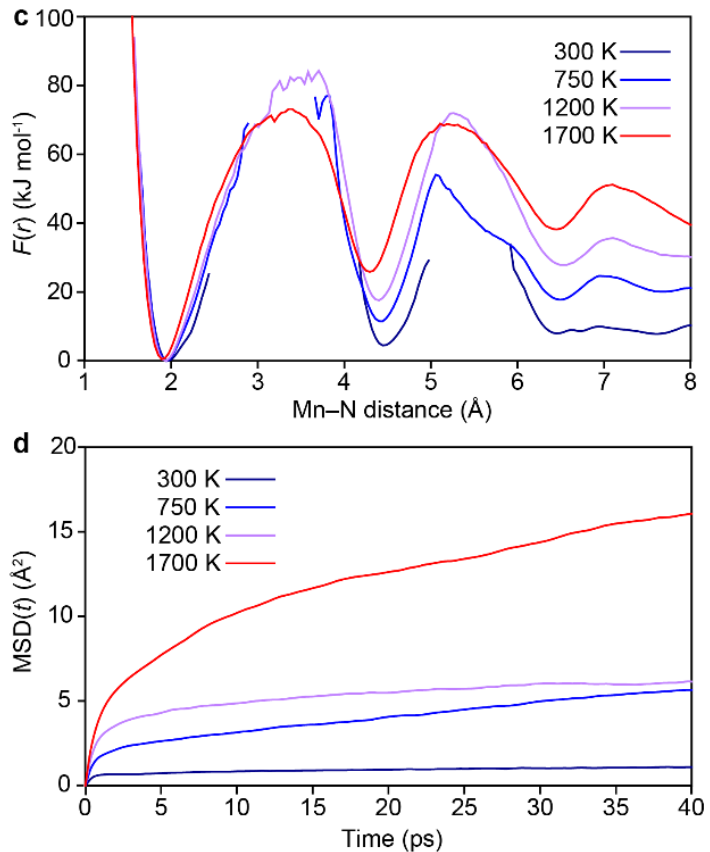

Figure 2. Structural insights into melting and glass structure. a, ${ }^{13} \mathrm{C}$ Double adiabatic echo MAS NMR spectra of crystalline [TPrA] $\left[\mathrm{Mn}(\mathrm{Dca})_{3}\right]$ before heating (pale green), after melt-quenching (green), crystalline $[\operatorname{TPrA}]\left[\mathrm{Fe}(\mathrm{Dca})_{3}\right]$ (pale red), after melt-quenching (red), crystalline $[\mathrm{TPrA}]\left[\mathrm{Co}(\mathrm{Dca})_{3}\right]$ before heating (pale blue) and after melt-quenching (blue). Magnified views of the 200 to -100 ppm region (within box) are shown on the right hand side with spectral assignments. Spectra were processed with exponential line broadenings (of $20 \mathrm{~Hz}$ ), appropriate for the magnified views shown in order to capture the various spectral features, while the overlaid views in the 6000 to $1000 \mathrm{ppm}$ paramagnetic shifts region show data processed with increased line broadenings (of $200 \mathrm{~Hz}$ ) taking into account the larger linewidths of the $\mathrm{NCN}$ resonances of the Dca ligand. $\mathrm{C}_{3} \mathrm{H}_{3} \mathrm{~N}_{3}$ corresponds to triazine-based structures. Asterisks $\left({ }^{*}\right)$ denote spinning sidebands. b. Evolution of the partial radial distribution function $g_{\mathrm{ij}}(r)$ for $\mathrm{Mn}-\mathrm{N}$ distances in [TPrA] $\left[\mathrm{Mn}(\mathrm{Dca})_{3}\right]$ at temperatures going from $300 \mathrm{~K}$ (navy blue) to $1700 \mathrm{~K}$ (red), from first principles molecular dynamics. c, Potential of mean force $F(r)$ along the $\mathrm{N}-\mathrm{Mn}$ distance coordinate at different temperatures. The discontinuities of some of the data arise from $F(r)$ being illdefined null values of $g_{\mathrm{Mn}-\mathrm{N}}(r)$. d, Mean square displacement as a function of time $\operatorname{MSD}(t)$ for [TPrA][Mn(Dca) $)_{3}$, for temperatures ranging from $300 \mathrm{~K}$ (navy blue) to $1700 \mathrm{~K}$ (red). 
Experimental evidence for the decoordination of Dca ligands during the melting process arises from an additional resonance at $120 \mathrm{ppm}$ in the spectra for $a_{g}[\operatorname{TPr}]\left[\mathrm{Fe}(\mathrm{Dca})_{3}\right]$, which is assigned to a 'free' Dca ligand ${ }^{22}$. A further peak at 159 ppm also indicates that triazine-based structures may be formed during/after melting ${ }^{22,23}$. This is supported by infra-red spectroscopy measurements (Supplementary Fig. 17), which show the appearance of two new absorption bands at $1629-1634 \mathrm{~cm}^{-1}$ and $802-806 \mathrm{~cm}^{-1}$ in the spectra for all $a_{g}[\operatorname{TPrA}]\left[M(D c a)_{3}\right]$ samples, consistent with prior reports of high temperature conversion of Dca to triazine-based structures in coordination polymers ${ }^{24}$. Diffuse reflectance UV-Vis spectroscopy demonstrated that decoordination of Dca ligands is accompanied by a change in metal coordination environment to 5-coordinate, with distorted octahedral geometries (Supplementary Fig. 18) ${ }^{25}$.

Temperature dependent DC magnetic susceptibility measurements were carried out, and the variation of $X_{\mathrm{M}} T$ ( $X_{\mathrm{M}}$ : molar magnetic susceptibility) as a function of $T$ demonstrated antiferromagnetic coupling for all samples at low temperatures (Supplementary Fig. 19) ${ }^{26}$. Interestingly, room temperature $X_{\mathrm{M}} T$ values for the glasses were smaller than those for the corresponding crystalline phases, indicating a reduction in oxidation state for a proportion of metal centres. These differences were used to calculate the percentage of metal ions reduced to $\mathrm{M}^{0}$ upon melt quenching in each case $\left(a_{g}[\operatorname{TPr} A]\left[\mathrm{Mn}(\mathrm{Dca})_{3}\right]-18.7 \%, a_{\mathrm{g}}[\mathrm{TPrA}]\left[\mathrm{Fe}(\mathrm{Dca})_{3}\right]-22.0 \%\right.$ and $\left.a_{g}[\operatorname{TPr} A]\left[\mathrm{Co}(\mathrm{Dca})_{3}\right]-15.3 \%\right)^{27}$. Despite this reduction, no significant spontaneous magnetization (Supplementary Fig. 20) is observed in the magnetization vs. magnetic field variation at room temperature (especially for $\left.a_{g}[\operatorname{TPr}]\left[\mathrm{Co}(\mathrm{Dca})_{3}\right]\right)$. We ascribe this to a large separation between $\mathrm{M}^{0}$ species in the glassy state.

\section{Atomistic Insight into Melting}

X-ray total scattering experiments were performed to provide an atomic level insight into the bonding within the melt quenched glasses. Room temperature total scattering data of $a_{g}[\operatorname{TPrA}]\left[\mathrm{M}(\mathrm{Dca})_{3}\right]$ reveal smooth broad humps without any Bragg peaks (Supplementary Fig. 21). The X-ray pair distribution functions (PDFs), $D(r)$, were extracted after appropriate data corrections (Supplementary Fig. 22) using experimental pycnometric densities of both crystalline and glass materials (Table 2). 
Similarities in $D(r)$ between crystalline and glass samples were noted at $r=\sim 1.3 \AA$, which contains contributions from $\mathrm{C}-\mathrm{C}, \mathrm{C}-\mathrm{N}$ (including $\mathrm{C} \equiv \mathrm{N}$ ) atom pairs, and at $r=$ $2.05-2.25 \AA$, which is ascribed predominantly to the M-N correlation (Supplementary Figs. 22- 24). The movement of this peak to lower $r$ from $\mathrm{Mn}-\mathrm{N}$ to $\mathrm{Fe}-\mathrm{N}$ and to $\mathrm{Co}-\mathrm{N}$ agrees well with the experimentally reported $\mathrm{M}-\mathrm{N}$ distances (Supplementary Fig. 23b). All PDFs contain evidence of correlations at $8.2 \AA$, which correspond to the repeat distance of the simplified primitive perovskite unit cell, including the weaklyweighted M-M distance (Supplementary Fig. 23c). As expected peaks ascribed to longer range interatomic correlations broaden and weaken, indicating a loss in longrange order upon melt quenching ${ }^{28}$. Interestingly, the peak at $3.3 \AA$, which belongs to the $\mathrm{M}-\mathrm{N}-\mathrm{C}$ correlation, broadens upon glass formation. The same is also true of the peak at $4.7 \AA$, which is ascribed to $\mathrm{M}-\mathrm{N}-\mathrm{C}-\mathrm{N}$, and a $\mathrm{C}-\mathrm{C}$ correlation between two neighboring Dca linkers. This supports linker decoordination upon melting.

First-principles molecular dynamics (FPMD) simulations were then employed, in order to characterize the microscopic evolution of [TPrA] [Mn(Dca) 3 ] upon melting (Fig. 2bd). The dynamic nature of bond breaking prevented the use of classical force fields, and so FPMD simulations based on a quantum chemical description of the system at the density functional theory level were chosen (Methods). Four separate MD simulations were performed on the crystalline material, at 300, 750, 1200, and 1700 K. Structural, dynamical, and thermodynamic properties were analysed along each trajectory.

The PDFs at each temperature were calculated, and show the expected significant thermal broadening for $\mathrm{Mn}-\mathrm{N}$ distances, in addition to the loss of long-range order ( $r$ $>6 \AA$ ) at the higher temperatures (Fig. 2b). The generalized Lindemann ratio was calculated for the Mn-N peak width, and found to exceed the Lindemann ratio ${ }^{29}$ between 750 and $1200 \mathrm{~K}$ (Supplementary Table 3). Analysis of the $\mathrm{N}-\mathrm{Mn}-\mathrm{N}$ angles also confirm deviation from a perfect octahedral environment upon heating (Supplementary Fig. 25), with broadening of the $\mathrm{N}-\mathrm{Mn}-\mathrm{N}$ bond angle peak centered at $90^{\circ}$. Analysis of the mean square displacement of [TPrA][Mn(Dca) 3 ] over time (Fig. 2d) confirmed the liquid-like nature of the resulting melt, with a transition from restricted motion (less than $1 \AA^{2}$ ) resulting from framework vibrations at $300 \mathrm{~K}$, to diffusive behaviour at $750 \mathrm{~K}$ and higher temperatures. 
Observation of the trajectories revealed breaking and reformation of $\mathrm{Mn}-\mathrm{N}$ bonds in the liquid state, in addition to significant movement of the propyl groups of the TPrA cations, starting at $1200 \mathrm{~K}$. A series of free energy profiles from the Mn-N PDFs was therefore calculated (Fig. 2c). These potentials of mean force, i.e. $F(r)=-k T \ln g(r)$, are expressed as a function of the $\mathrm{Mn}-\mathrm{N}$ distance, and, importantly, show that the mechanism of the melting is similar to that observed previously in metal-organic frameworks of the ZIF family ${ }^{10}$. This mechanistic description was further confirmed from the distribution of the instantaneous coordination of Mn ions (Supplementary Fig. 26), demonstrating a reduction in the number of 6-fold coordinated Mn atoms alongside an accompanying increase in the number of 5-fold coordinated $\mathrm{Mn}$ atoms. From these data, we were able to fit the concentration of 5-fold coordinated $\mathrm{M}^{2+}$ ions, considered as a "defect" in the structure, with $n_{d} \propto \exp \left(-\Delta_{f} H_{d} / R T\right)$ and estimate an enthalpy for formation of $\Delta_{\mathrm{f}} H_{\mathrm{d}} \sim 91 \mathrm{~kJ} / \mathrm{mol}$ (estimated between $1200 \mathrm{~K}$ and $1700 \mathrm{~K}$ ). The value of the free energy barrier to melting (Fig. 2C) was estimated as $\sim 85 \mathrm{~kJ} \mathrm{~mol}^{-}$ 1 at $1200 \mathrm{~K}$, i.e. similar to other framework materials ${ }^{10}$. This significant barrier confirms that, as in conventional solids, melting occurs through a rare barrier-crossing event. However, in contrast with the case of porous MOFs, where this barrier is stronglytemperature dependent, here the impact of temperature is smaller; meaning the activation entropy involved is lower. We link this to a higher metal node coordination number in hybrid perovskites compared to zeolitic imidazolate frameworks.

\section{Electrical Conductivity}

Frequency dependent conductivity measurements were carried out to probe the charge-transport behaviour of the $a_{\mathrm{g}}[\operatorname{TPr}]\left[\mathrm{M}(\mathrm{Dca})_{3}\right]$ samples, and values of the inphase $A C$ impedance $\left(Z^{\prime}\right)$ plotted with the corresponding out of phase component $(Z ")^{30}$ (Fig. 3a). Values of DC-resistances (DC-R) were evaluated after fitting of the semicircular Cole-Cole diagram. We ascribe the low frequency dispersion as the result of electrode polarization occurring as soon as the material is subjected to an oscillating electric field ${ }^{31}$. Room temperature DC conductivities $\left(\sigma_{\mathrm{RT}}\right)$ of $0.8 \times 10^{-4} \mathrm{~S} \mathrm{~m}^{-1}, 0.28 \times$ $10^{-3} \mathrm{~S} \mathrm{~m}^{-1}$ and $0.9 \times 10^{-1} \mathrm{~S} \mathrm{~m}^{-1}$ for the $\mathrm{Mn}$, Co and Fe based glasses characterize these as moderately conducting materials (Table 2 ).

Values of dielectric permittivity $\varepsilon^{\prime}$ were evaluated from the electric modulus spectra (Supplementary Figs. 27 and 28). The absolute $\varepsilon^{\prime}$ values for $a_{g}[\operatorname{TrA}]\left[\mathrm{Fe}(\mathrm{Dca})_{3}\right]$ are 
unsaturated at the limit of the instrumental frequency, revealing continuous dielectric polarization with applied oscillating electric fields up to $2 \mathrm{MHz}$. The corresponding values for $a_{g}[\operatorname{TPrA}]\left[\mathrm{Mn}(\mathrm{Dca})_{3}\right]\left(\varepsilon^{\prime}=32\right)$ and $a_{\mathrm{g}}[\operatorname{TPrA}]\left[\mathrm{Co}(\mathrm{Dca})_{3}\right]\left(\varepsilon^{\prime}=30\right)$ are saturated at this limit and are higher than other standard glass materials e.g. pyrex $\left(\varepsilon^{\prime} \sim 4.5\right)$ or reported ZIF glasses $\left(\varepsilon^{\prime} \sim 2.0\right)^{32,33}$, though are significantly less compared to inorganic perovskites $\left(\varepsilon^{\prime}>80\right)^{34}$.
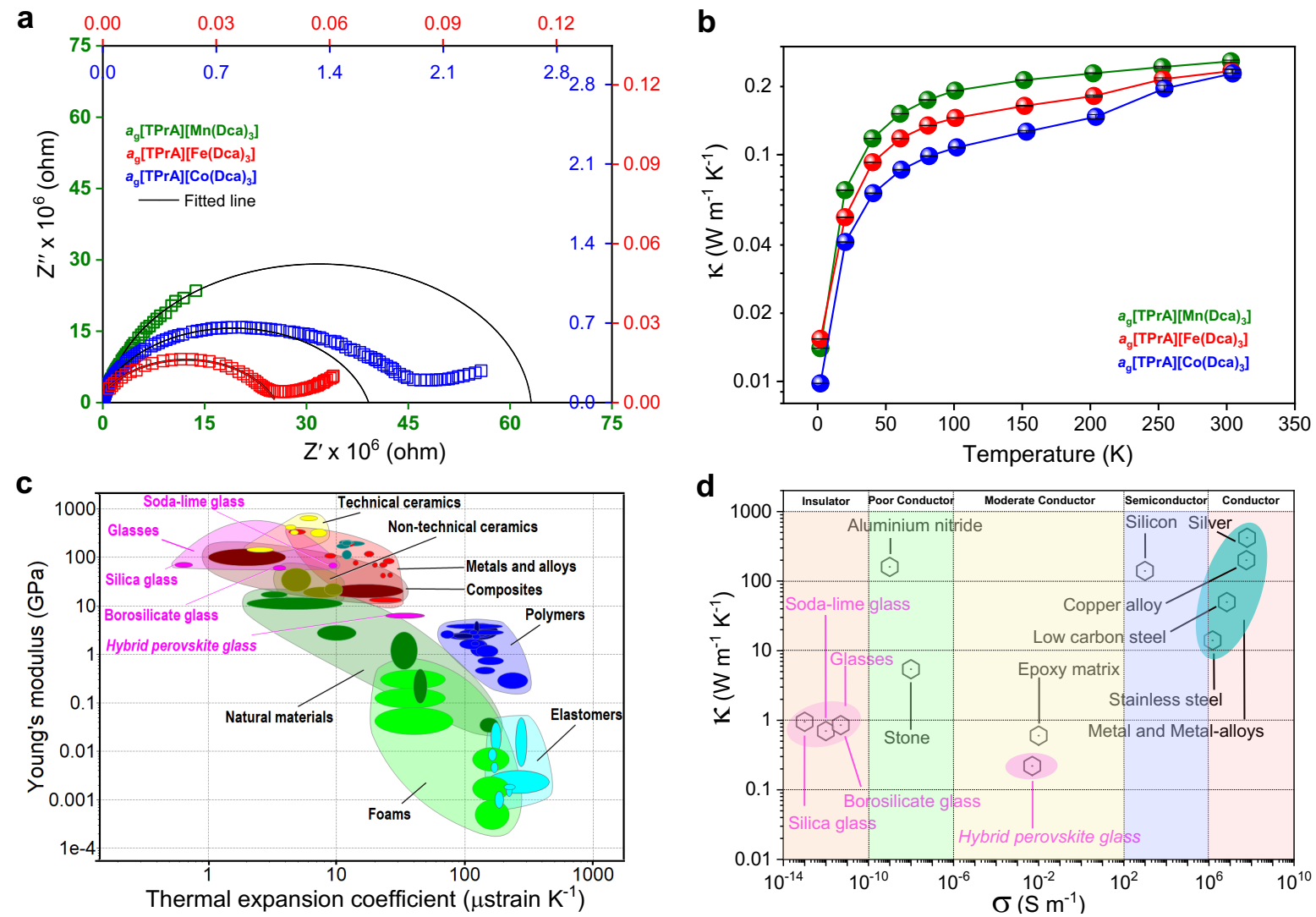

Figure 3. Physical properties of hybrid perovskite glasses. a, Cole-Cole diagram of real ( $\left.Z^{\prime}\right)$ and imaginary $(Z ")$ parts of impedance values for $a_{9}[\operatorname{TPr}]\left[\mathrm{M}(\mathrm{Dca})_{3}\right]$ at $300 \mathrm{~K}$. The cut-off point of theoretical line (black) at $\mathrm{x}$-axis shows values of DC-resistance. Low frequency dispersion occurs due to electrode polarization. b, Logarithmic variation of thermal conductivity $(\kappa)$ as a function of temperature for $a_{g}[\operatorname{TPrA}]\left[\mathrm{M}(\mathrm{Dca})_{3}\right]$ from 2 to $300 \mathrm{~K}$. c, An Ashby plot of Young's modulus $(E)$ vs. thermal expansion coefficient ( $\alpha$ ). Representative values of $\alpha$ were calculated from the data in Fig. 1c. d, An Ashby plot of thermal conductivity $(\kappa)$ vs. electrical conductivity $(\sigma)$ at $300 \mathrm{~K}$. Both $\mathbf{c}$ and $\mathbf{d}$ show the comparison of hybrid perovskite glasses with various classes of materials including other glass types (pink font).

\section{Thermal Conductivity}

The thermal conductivity of glasses is of great importance given the applications of inorganics in e.g. high-efficiency thermoelectric materials ${ }^{35}$, waste-heat power 
generation and solid-state Peltier coolers ${ }^{36}$. The heat conductivity of $a_{g}[\operatorname{PrA}]\left[\mathrm{M}(\mathrm{Dca})_{3}\right]$ series was probed, finding absolute values of thermal conductivity at room temperature $\left(\kappa_{\mathrm{RT}}\right)$ of $0.258 \mathrm{~W} \mathrm{~m}^{-1} \mathrm{~K}^{-1}$ for $a_{\mathrm{g}}[\operatorname{TPrA}]\left[\mathrm{Mn}(\mathrm{Dca})_{3}\right], 0.234 \mathrm{~W} \mathrm{~m}^{-1} \mathrm{~K}^{-1}$ for $a_{\mathrm{g}}[\operatorname{TPrA}]\left[\mathrm{Fe}(\mathrm{Dca})_{3}\right]$ and $0.228 \mathrm{~W} \mathrm{~m}^{-1} \mathrm{~K}^{-1}$ for $a_{\mathrm{g}}[\operatorname{TPrA}]\left[\mathrm{Co}(\text { Dca })_{3}\right]$ (Fig. 3b). This is lower than the recently reported $\mathrm{Pb}$-halide perovskites ${ }^{37,38}\left(\sim 0.40-0.50 \mathrm{~W} \mathrm{~m}^{-1} \mathrm{~K}^{-1}\right)$, various crystalline metal organic frameworks (MOF-5 $5^{39} \sim 0.32 \mathrm{~W} \mathrm{~m}^{-1} \mathrm{~K}^{-1}$, perovskite MOF ${ }^{40} \sim$ $\left.1.3 \mathrm{~W} \mathrm{~m}^{-1} \mathrm{~K}^{-1}\right)$ and zeolitic imidazolate framework (ZIF-8 $\left.{ }^{41} \sim 0.33 \mathrm{~W} \mathrm{~m}^{-1} \mathrm{~K}^{-1}\right)$ systems, and significantly less in comparison to other glass architectures, e.g. doped silicate or borosilicate inorganic glasses ${ }^{42}\left(\sim 1 \mathrm{~W} \mathrm{~m}^{-1} \mathrm{~K}^{-1}\right)$.

The isotropic nature of glass and the associated constant phonon mean free path $(\lambda$ $\left.=\lambda_{0}\right)$ with temperature ${ }^{43}$, mean that $\kappa$ varies only with specific heat $\left(c_{v}\right)$, and decreases as temperature decreases ${ }^{44}$.

$$
\kappa=c_{\mathrm{v}} u_{\rho \mathrm{g}} \lambda_{\mathrm{p}}
$$

where $u_{\rho g}=$ phonon group velocity ${ }^{43}, \lambda_{\mathrm{p}}=$ phonon mean free path.

However, $\kappa$ drops dramatically in the perovskite glasses here at temperatures below $110 \mathrm{~K}$, when the wavelength of dominant thermally activated phonons become significantly larger than the correlation length (approximate unit cell length $D^{58}$, equation 3). The temperature where $\kappa$ seems to decrease drastically is considered as the limiting temperature $\left(T_{0}\right)$ at which $\lambda_{0}$ is no longer constant and tends to increase. This is clearly visible from the point of bifurcation of the successive cooling-heating curves of thermal conductivity (Supplementary Fig. 29). The relation between thermal energy and lattice vibrations (equation 3$)^{43}$ may therefore be used to obtain the approximate correlation length within the melt-quenched glass samples.

$$
k T_{0}=\frac{h u_{\rho \mathrm{g}}}{D}
$$

where $T_{0}=$ the temperature from which phonon mean free path increases ${ }^{43}, k=$ Boltzmann constant, $h=$ Planck constant. Values of this correlation length $(D)$ obtained are $16.87 \AA( \pm 0.10 \AA)$ for $a_{g}[\operatorname{TPrA}]\left[\mathrm{Mn}(\mathrm{Dca})_{3}\right]\left(T_{0}=112 \mathrm{~K}, \pm 2 \mathrm{~K}\right), 17.18 \AA( \pm 0.21 \AA)$ for $a_{\mathrm{g}}[\operatorname{TPrA}]\left[\mathrm{Fe}(\mathrm{Dca})_{3}\right]\left(T_{0}=110 \mathrm{~K}, \pm 3 \mathrm{~K}\right)$ and $22.23 \AA( \pm 0.32 \AA)$ for $a_{\mathrm{g}}[\operatorname{TPrA}]\left[\mathrm{Co}(\mathrm{Dca})_{3}\right]\left(T_{0}=85 \mathrm{~K}, \pm 5 \mathrm{~K}\right)$. These values are, as expected given the disorder, smaller than the unit cells of the crystalline [TPrA][M(Dca $\left.)_{3}\right]$ samples (Supplementary Fig. 1). The largest reduction is however still $<6 \%$ (for 
$\left.a_{g}[\operatorname{TPrA}]\left[\mathrm{Mn}(\mathrm{Dca})_{3}\right]\right)$, indicating the short-medium range order present within the glass may bear some resemblance to the crystalline phase.

\section{Mechanical Properties}

Gas pycnometry results show relatively high values of glass-crystal network density difference $\left(\rho_{g}-\rho_{c}\right) / \rho_{g}=\Delta \rho / \rho_{g}$, e.g., $0.073( \pm 0.005)$ for $[T P r A]\left[M n(D c a)_{3}\right], 0.076( \pm 0.003)$ for $[\operatorname{TPrA}]\left[\mathrm{Fe}(\mathrm{Dca})_{3}\right]$ and $0.03( \pm 0.004)$ for $[\operatorname{TPrA}]\left[\mathrm{Co}(\mathrm{Dca})_{3}\right]$ respectively. Absolute values of the Young's modulus $(E)$ of $6.65 \mathrm{GPa}$ for $a_{g}[\operatorname{TPrA}]\left[\mathrm{Mn}(\mathrm{Dca})_{3}\right], 5.85 \mathrm{GPa}$ for $a_{\mathrm{g}}[\operatorname{TPrA}]\left[\mathrm{Fe}(\mathrm{Dca})_{3}\right]$ and $6.98 \mathrm{GPa}$ for $a_{\mathrm{g}}[\operatorname{TPrA}]\left[\mathrm{Co}(\mathrm{Dca})_{3}\right]$ were elucidated using nanoindentation (Table 2, Supplementary Fig. 30). Such values are of the same magnitude as existing metal-organic framework glasses, despite the densities of the perovskite materials being substantially higher ${ }^{45}$. This points toward the dominant role of coordination bonding in determining the intermediate compliance of both MOF-and hybrid perovskite-derived glasses between organics and inorganics ${ }^{46}$ (Fig. 3c).

Table 2: Physical properties of hybrid perovskite glasses.

\begin{tabular}{|c|c|c|c|c|c|c|c|}
\hline Samples & $\begin{array}{c}E \\
(\mathrm{GPa})\end{array}$ & $\begin{array}{c}\rho_{\mathrm{c}} \\
\left(\mathrm{g} \mathrm{cm}^{-3}\right) \\
\end{array}$ & $\begin{array}{c}\rho_{\mathrm{g}} \\
\left(\mathrm{g} \mathrm{cm}^{-3}\right)\end{array}$ & $\Delta \rho / \rho_{g}$ & $\begin{array}{c}\sigma_{\mathrm{RT}} \times 10^{-3} \\
\left(\mathrm{~S} \mathrm{~m}^{-1}\right)\end{array}$ & $\begin{array}{c}\varepsilon^{\prime} \text { at } 2 \mathrm{MHz} \\
(\tan \delta)\end{array}$ & $\begin{array}{c}K_{R T} \\
\left(W_{m^{-1}} K^{-1}\right) \\
\end{array}$ \\
\hline$a_{\mathrm{g}}[\mathrm{TPrA}]\left[\mathrm{Mn}(\mathrm{Dca})_{3}\right]$ & $\begin{array}{c}6.65 \\
( \pm 0.08)\end{array}$ & $\begin{array}{c}1.237 \\
( \pm 0.005)\end{array}$ & $\begin{array}{c}1.335 \\
( \pm 0.006)\end{array}$ & $\begin{array}{c}0.073 \\
( \pm 0.005)\end{array}$ & 0.08 & $32(0.03)$ & 0.258 \\
\hline$a_{g}[\operatorname{TPrA}]\left[\mathrm{Fe}(\mathrm{Dca})_{3}\right]$ & $\begin{array}{c}5.85 \\
( \pm 0.09)\end{array}$ & $\begin{array}{c}1.225 \\
( \pm 0.004)\end{array}$ & $\begin{array}{c}1.326 \\
( \pm 0.002)\end{array}$ & $\begin{array}{c}0.076 \\
( \pm 0.003)\end{array}$ & 94.5 & $-a^{a}$ & 0.234 \\
\hline$a_{\mathrm{g}}[\mathrm{TPrA}]\left[\mathrm{Co}(\mathrm{Dca})_{3}\right]$ & $\begin{array}{c}6.98 \\
( \pm 0.07)\end{array}$ & $\begin{array}{c}1.245 \\
( \pm 0.005)\end{array}$ & $\begin{array}{c}1.283 \\
( \pm 0.004)\end{array}$ & $\begin{array}{c}0.030 \\
( \pm 0.004)\end{array}$ & 0.28 & $30(0.07)$ & 0.228 \\
\hline
\end{tabular}

${ }^{a}$ Unsaturated at the limit of the instrumental frequency, $2 \mathrm{MHz}$.

\section{Discussion}

The much lower melting point of the hybrid perovskites $\left(T_{\mathrm{m}} \sim 250^{\circ} \mathrm{C}\right)$ is in accordance with their substantially lower enthalpies of fusion $\Delta H_{\mathrm{f}}\left(\sim 46-62 \mathrm{~kJ} \mathrm{~mol}^{-1}\right.$; Fig. 1b, Table 2) compared to other materials such as conventional quartz-silica $\left(\sim 911 \mathrm{~kJ} \mathrm{~mol}^{-}\right.$ $\left.{ }^{1}\right)^{47}$. This, alongside low activation energies $E_{\mathrm{a}}$ for the glass transition of $\sim 20 \mathrm{~kJ} \mathrm{~mol}^{-1}$ compared to inorganics $\left(\sim 100 \mathrm{~kJ} \mathrm{~mol}^{-1}\right)^{48}$, point to the greater accessibility, and processability of the liquid state, even when compared to existing MOF-glasses ${ }^{46}$. As 
with examples from the zeolitic imidazolate framework family, the rare event of metallinker bond breakage leads to under-coordination of $\mathrm{M}^{2+}$ ions in a diffusive liquid state.

Considerable differences with glass formation in the ZIF family are however present, and include (i) a lower dependence of melting upon temperature, (ii) complex competing metal reduction and ligand cyclisation processes, and (iii) the presence of tertiary amine cations, which underpins moderate electrical conductivities $\left(10^{-2}-10^{-4} \mathrm{~S}\right.$ $\mathrm{m}^{-1}$ ) found in the glasses. We note that these are greater than various cation doped inorganic ion-conducting silicate or borosilicate glasses by an approximate factor of two ${ }^{49}$. This may be due to relatively sluggish reordering of the larger Dca units in the liquid state here, as opposed to those in inorganic melts. The relatively high values of dielectric permittivity with low dielectric losses (Table 2) may suggest the glasses as good candidates for low-loss, medium-permittivity integrated device applications.

Coupled with the very low values of thermal conductivity found $\left(\sim 0.2 \mathrm{~W} \mathrm{~m}^{-1} \mathrm{~K}^{-1}\right)$, these properties may suggest possible uses in thermoelectric settings of efficient energy conversion and waste-heat power generation ${ }^{36}$ (Fig. 3d). Such properties, alongside the dissimilar structure, melting and chemical components of hybrid perovskites, set them apart from existing coordination polymer and MOF glasses, as a new family of functional hybrid glass-formers.

\section{Acknowledgements}

B.K.S. thanks the Royal Society and the Science and Engineering Research Board of India (SERB) for their combined support in Newton International Fellowship (NIFIR1|180163). A.R.H. thanks the EPSRC for a Doctoral Training Studentship, T.D.B. the Royal Society for a University Research Fellowship (UF150021) and a research grant (RG94426), and the University of Canterbury Te Whare Wānanga o Waitaha, New Zealand, for a University of Cambridge Visiting Canterbury Fellowship. M.D. and F.-X.C. acknowledge financial support from the Agence Nationale de la Recherche under the project "MATAREB" (ANR-18-CE29-0009-01) and access to high-performance computing platforms provided by GENCl grant A0070807069. B.K.S. acknowledges Robert Cornell (University of Cambridge) for his help to perform the dynamic-mechanical measurements and F.B. thanks Dr. Kevin J. Sanders (McMaster University) for assistance with the NMR pulse sequences.

\section{Author contributions}

B.K.S. and T.D.B. designed the project. A.R.H. and F.B. performed all NMR experiments and analyzed the data. D.A.K. performed all X-ray total scattering experiments and analyzed the data. M.D. and F.- 
X.C. performed molecular simulations and analyzed the data. B.K.S. collected and analyzed all other data. All authors participated in manuscript writing.

\section{Competing interests}

The authors declare no competing financial interests.

\section{References}

1. Eames, C. et al. lonic transport in hybrid lead iodide perovskite solar cells. Nat. Commun. 6, 7497 (2015).

2. Frost, J. M. et al. Atomistic origins of high-performance in hybrid halide perovskite solar cells. Nano Lett. 14, 2584-2590 (2014).

3. Luo, D. et al. Enhanced photovoltage for inverted planar heterojunction perovskite solar cells. Science 360, 1442-1446 (2018).

4. Bermúdez-García, J. M. et al. Role of Temperature and Pressure on the Multisensitive Multiferroic Dicyanamide Framework [TPrA][Mn(dca) 3 ] with Perovskite-like Structure. Inorg. Chem. 54, 11680-11687 (2015).

5. Wu, Y. et al. [Am]Mn(H 2 POO) 3 : A New Family of Hybrid Perovskites Based on the Hypophosphite Ligand. J. Am. Chem. Soc. 139, 16999-17002 (2017).

6. Batten, S. R. et al. Terminology of metal-organic frameworks and coordination polymers (IUPAC recommendations 2013). Pure Appl. Chem. 85, 1715-1724 (2013).

7. Furukawa, H., Cordova, K. E., O'Keeffe, M. \& Yaghi, O. M. The chemistry and applications of metal-organic frameworks. Science 341, 1230444 (2013).

8. Ricco, R. et al. Emerging applications of metal-organic frameworks. CrystEngComm 18, 6532-6542 (2016).

9. Bennett, T. D. \& Horike, S. Liquid, glass and amorphous solid states of coordination polymers and metal-organic frameworks. Nat. Rev. Mater. 3, 431-440 (2018).

10. Gaillac, R. et al. Liquid metal-organic frameworks. Nat. Mater. 16, 1149-1154 (2017).

11. Morris, R. E. \& Brammer, L. Coordination change, lability and hemilability in metal-organic frameworks. Chem. Soc. Rev. 46, 5444-5462 (2017).

12. Bermúdez-García, J. M. et al. Multiple phase and dielectric transitions on a novel multi-sensitive [TPrA][M(dca) 3 ] (M: Fe 2+, Co 2+ and Ni 2+ ) hybrid inorganic-organic perovskite family. J. Mater. Chem. C 4, 4889-4898 (2016).

13. Bermúdez-García, J. M. et al. Giant barocaloric effect in the ferroic organicinorganic hybrid [TPrA][Mn(dca)3] perovskite under easily accessible pressures. Nat. Commun. 8, 15715 (2017).

14. Umeyama, D., Horike, S., Inukai, M., Itakura, T. \& Kitagawa, S. Reversible 
Solid-to-Liquid Phase Transition of Coordination Polymer Crystals. J. Am. Chem. Soc. 137, 864-870 (2015).

15. Menard, K. P. \& Menard, N. R. Dynamic Mechanical Analysis in the Analysis of Polymers and Rubbers. in Encyclopedia of Polymer Science and Technology 1-33 (Wiley, 2015).

16. Pell, A. J., Pintacuda, G. \& Grey, C. P. Paramagnetic NMR in solution and the solid state. Prog. Nucl. Magn. Reson. Spectrosc. 111, 1-271 (2019).

17. Ishii, Y., Wickramasinghe, N. P. \& Chimon, S. A New Approach in 1D and 2D 13 C High-Resolution Solid-State NMR Spectroscopy of Paramagnetic Organometallic Complexes by Very Fast Magic-Angle Spinning. J. Am. Chem. Soc. 125, 3438-3439 (2003).

18. Kervern, G., Pintacuda, G. \& Emsley, L. Fast adiabatic pulses for solid-state NMR of paramagnetic systems. Chem. Phys. Lett. 435, 157-162 (2007).

19. Gougeon, R., Delmotte, L., Reinheimer, P., Meurer, B. \& Che, J. M. HighResolution Solid-State Nuclear Magnetic Resonance Study of the Tetrapropylammonium Template in a Purely Siliceous MFI-Type Zeolite. Magn. Resoannce Chem. 36, 415-421 (1998).

20. Hing, A. W., Vega, S. \& Schaefer, J. Transferred-Echo Double-Resonance NMR. J. Magn. Reson. 96, 205-209 (1992).

21. Tucker, M. C. et al. Hyperfine Fields at the Li Site in LiFePO4 -Type Olivine Materials for Lithium Rechargeable Batteries: A 7Li MAS NMR and SQUID Study. J. Am. Chem. Soc. 124, 3832-3833 (2002).

22. Täuber, K., Dani, A. \& Yuan, J. Covalent Cross-Linking of Porous Poly(ionic liquid) Membrane via a Triazine Network. ACS Macro Lett. 6, 1-5 (2017).

23. Kroke, E. et al. Tri-s-triazine derivatives. Part I. From trichloro-tri-s-triazine to graphitic C3N4 structures. New J. Chem. 26, 508-512 (2002).

24. Jürgens, B., Höppe, H. A. \& Schnick, W. Synthesis, crystal structure, vibrational spectroscopy, and thermal behaviour of lead dicyanamide $\mathrm{Pb}[\mathrm{N}(\mathrm{CN}) 2] 2$. Solid State Sci. 4, 821-825 (2002).

25. Bo, S.-H. et al. Thin-Film and Bulk Investigations of LiCoBO 3 as a Li-lon Battery Cathode. ACS Appl. Mater. Interfaces 6, 10840-10848 (2014).

26. Schlueter, J. A., Manson, J. L. \& Geiser, U. Structural and Magnetic Diversity in Tetraalkylammonium Salts of Anionic M [N(CN) 2 ] 3 - ( M = Mn and Ni) Three-Dimensional Coordination Polymers. Inorg. Chem. 44, 3194-3202 (2005).

27. Frentzel-Beyme, L. et al. Porous purple glass - a cobalt imidazolate glass with accessible porosity from a meltable cobalt imidazolate framework. J. Mater. Chem. A 7, 985-990 (2019).

28. Chen, W. et al. Glass Formation of a Coordination Polymer Crystal for Enhanced Proton Conductivity and Material Flexibility. Angew. Chemie - Int. Ed. 55, 5195-5200 (2016). 
29. Chakravarty, C., Debenedetti, P. G. \& Stillinger, F. H. Lindemann measures for the solid-liquid phase transition. J. Chem. Phys. 126, 204508 (2007).

30. Shaw, B. K. \& Saha, S. K. Giant magnetoresistance and magneto-dielectric effects in a charge transfer metal complex for multiferroic applications. J. Phys. Chem. C 116, 20700-20707 (2012).

31. Leo, C. J., Subba Rao, G. V. \& Chowdari, B. V. R. Fast ion conduction in the Li-analogues of Nasicon, Li1 + x[(Ta1 - xGex)Al](PO4)3. J. Mater. Chem. 12, 1848-1853 (2002).

32. Krishtab, M. et al. Vapor-deposited zeolitic imidazolate frameworks as gapfilling ultra-low-k dielectrics. Nat. Commun. 10, 3729 (2019).

33. Ryder, M. R. et al. Dielectric Properties of Zeolitic Imidazolate Frameworks in the Broad-Band Infrared Regime. J. Phys. Chem. Lett. 9, 2678-2684 (2018).

34. Homes, C. C. Optical Response of High-Dielectric-Constant PerovskiteRelated Oxide. Science 293, 673-676 (2001).

35. Snyder, G. J. \& Toberer, E. S. Complex thermoelectric materials. Nat. Mater. 7, 105-114 (2008).

36. Bell, L. E. Cooling, heating, generating power, and recovering waste heat with thermoelectric systems. Science 321, 1457-1461 (2008).

37. Ye, T. et al. Ultra-high Seebeck coefficient and low thermal conductivity of a centimeter-sized perovskite single crystal acquired by a modified fast growth method. J. Mater. Chem. C 5, 1255-1260 (2017).

38. Pisoni, A. et al. Ultra-low thermal conductivity in organic-inorganic hybrid perovskite CH3NH3PbI3. J. Phys. Chem. Lett. 5, 2488-2492 (2014).

39. Huang, B. L., McGaughey, A. J. H. \& Kaviany, M. Thermal conductivity of metal-organic framework 5 (MOF-5): Part I. Molecular dynamics simulations. Int. J. Heat Mass Transf. 50, 393-404 (2007).

40. Gunatilleke, W. D. C. B. et al. Thermal conductivity of a perovskite-type metalorganic framework crystal. Dalt. Trans. 46, 13342-13344 (2017).

41. Cui, B. et al. Thermal Conductivity of ZIF-8 Thin-Film under Ambient Gas Pressure. ACS Appl. Mater. Interfaces 9, 28139-28143 (2017).

42. Bansal, N. P. \& Doremus, R. H. Thermal Conductivity. in Handbook of Glass Properties 207-219 (Elsevier, 1986).

43. Kittel, C. Interpretation of the thermal conductivity of glasses. Phys. Rev. 75, 972-974 (1949).

44. Huang, B. L. et al. Thermal conductivity of a metal-organic framework (MOF5): Part II. Measurement. Int. J. Heat Mass Transf. 50, 405-411 (2007).

45. Bennett, T. D. et al. Melt-Quenched Glasses of Metal-Organic Frameworks. J. Am. Chem. Soc. 138, 3484-3492 (2016).

46. Qiao, A. et al. A metal-organic framework with ultrahigh glass-forming ability. Sci. Adv. 4, eaao6827 (2018). 
47. Richet, P. Viscosity and configurational entropy of silicate melts. Geochim. Cosmochim. Acta 48, 471-483 (1984).

48. Matsuishi, K., Nogi, K., Ohmori, J., Onari, S. \& Arai, T. Structural phase stability of Se clusters in zeolites. Zeitschrift fur Phys. D-Atoms Mol. Clust. 40, 530-533 (1997).

49. Bansal, N. P. \& Doremus, R. H. Electrical Conductivity. in Handbook of Glass Properties 381-449 (Elsevier, 1986).

50. Thurber, K. R. \& Tycko, R. Measurement of sample temperatures under magic-angle spinning from the chemical shift and spin-lattice relaxation rate of $79 \mathrm{Br}$ in $\mathrm{KBr}$ powder. J. Magn. Reson. 196, 84-87 (2009).

51. Morcombe, C. R. \& Zilm, K. W. Chemical shift referencing in MAS solid state NMR. J. Magn. Reson. 162, 479-486 (2003).

52. Bain, G. A. \& Berry, J. F. Diamagnetic Corrections and Pascal's Constants. J. Chem. Educ. 85, 532 (2008).

53. VandeVondele, J. et al. Quickstep: Fast and accurate density functional calculations using a mixed Gaussian and plane waves approach. Comput. Phys. Commun. 167, 103-128 (2005).

54. Bussi, G., Donadio, D. \& Parrinello, M. Canonical sampling through velocity rescaling. J. Chem. Phys. 126, 014101 (2007).

55. Perdew, J. P., Burke, K. \& Ernzerhof, M. Generalized Gradient Approximation Made Simple. Phys. Rev. Lett. 77, 3865-3868 (1996).

56. Grimme, S., Antony, J., Ehrlich, S. \& Krieg, H. A consistent and accurate ab initio parametrization of density functional dispersion correction (DFT-D) for the 94 elements H-Pu. J. Chem. Phys. 132, 154104 (2010).

57. Goedecker, S., Teter, M. \& Hutter, J. Separable dual-space Gaussian pseudopotentials. Phys. Rev. B 54, 1703-1710 (1996). 


\section{Materials and Methods}

\section{Thermal gravimetric analysis}

Simultaneous thermogravimetric and calorimetric analysis (TGA/Heat flow) were carried out in a SDT-Q600 apparatus (TA Instruments). Data were collected in the range from $25^{\circ} \mathrm{C}$ to $400{ }^{\circ} \mathrm{C}$ at a scan rate of $10^{\circ} \mathrm{C} \mathrm{min}{ }^{-1}$ under an Argon atmosphere.

\section{Heat flow analysis}

DSC measurements were conducted using a Netzsch 214 Polyma instrument. Samples were placed in an aluminum pan and heated up to their respective melting offset at a heating rate of $10^{\circ} \mathrm{C} \mathrm{min}-1$ under Argon atmosphere and rapidly quenched to room temperature to prepare the amorphous glass. To obtain the glass transition, the melted solids were cooled to $60^{\circ} \mathrm{C}$ at a same cooling rate of $10^{\circ} \mathrm{C} \mathrm{min}-1$, followed by a $2 \mathrm{~min}$ isothermal treatment, and then reheated at $10^{\circ} \mathrm{C} \mathrm{min}{ }^{-1}$ up to the targeted temperature.

\section{Thermomechanical analysis}

For $[\operatorname{TPrA}]\left[\mathrm{Mn}(\mathrm{Dca})_{3}\right]$ and $[\mathrm{TPrA}]\left[\mathrm{Fe}(\mathrm{Dca})_{3}\right]$, dense flat pieces of quenched-glass samples were used to determine the CTE and $T_{\mathrm{f}}$ values, however due to the irregular shape of the $[\operatorname{TPrA}]\left[\mathrm{Co}(\mathrm{Dca})_{3}\right]$ melted solid, a pelletized glass sample was used. In this technique, the linear expansion of the glasses is measured as a function of temperature at a standard TMA heating rate of $5^{\circ} \mathrm{C} \mathrm{min}-1$ with a standard applied force of $10 \mathrm{mN}$ by means of a dilatometer under $\mathrm{N}_{2}$ atmosphere in TMA-Q400 apparatus (TA Instruments).

\section{Dynamic mechanical analysis}

Glass transition relaxation dynamics were investigated using dynamic mechanical analyzer, DMA-Q800 (TA Instruments). To perform the measurements, amorphous powders were wrapped in an aluminum foil, in a rectangular sample geometry. The sample geometry was pre-calibrated with polycarbonate reference. Well-prepared specimens of equal masses and of even thickness (dimension of $\sim 35.0 \mathrm{~mm} \times 12.8$ $\mathrm{mm} \times 3.2 \mathrm{~mm}$ ) in parallel sides are finally placed in single cantilever (Supplementary Fig. 31). A slow heating rate of $2{ }^{\circ} \mathrm{C} \mathrm{min}-1$ is applied to minimize the thermal fluctuation and dipolar coupling (low loss/heat dissipation) with an applied frequency varying from 1-3 $\mathrm{Hz}$.

\section{Powder X-ray diffraction}

Ambient Temperature: $X$-ray powder diffraction (PXRD) patterns were recorded $(2 \theta=$ $10^{\circ}-60^{\circ}$ ) on a Bruker D8 Advance diffractometer (equipped with a LynxEye EX linear position sensitive detector) in Bragg-Brentano geometry using $\mathrm{Cu} \mathrm{Ka}(\lambda=1.540598$ $\AA$ ) source fitted with a Ni $0.012 \mathrm{~mm}$ filter. Data were collected in $2 \theta$ step size of $0.02^{\circ}$, with 10 s per step. 


\section{Scanning electron microscopy}

The surface morphologies of the hybrid perovskite glass samples were investigated using a high-resolution scanning electron microscope, FEI Nova Nano SEM 450. Palladium sputtering was used to reduce charging of the specimen.

\section{Nuclear magnetic resonance (NMR)}

Solid state NMR experiments were performed on a 9.4 T Bruker Avance III HD spectrometer equipped with a $1.3 \mathrm{~mm} \mathrm{HXY}$ magic angle spinning (MAS) probe in double resonance mode. The ${ }^{1} \mathrm{H}$ channel was tuned to $v_{0}\left({ }^{1} \mathrm{H}\right)=400.13 \mathrm{MHz}$ and the $X$ channel was tuned to $v_{0}\left({ }^{13} \mathrm{C}\right)=100.61 \mathrm{MHz}$. Spectra were recorded under an optimised approach for paramagnetic systems combining very fast MAS ${ }^{17}$ with double adiabatic echo detection and shaped pulses ${ }^{18}$. All NMR spectra were recorded at a spinning rate of $60 \mathrm{kHz}$, corresponding to a sample temperature of ca. $45{ }^{\circ} \mathrm{C}$ (as measured from the ${ }^{79} \mathrm{Br} N M R$ chemical shift change of $\mathrm{KBr}^{50}$ ), and pulses were applied at a radiofrequency field of $200 \mathrm{kHz}$ at an offset of $0 \mathrm{ppm}$ for [TPrA] $\left[\mathrm{Mn}(\mathrm{Dca})_{3}\right]$, and 2985 ppm for both [TPrA] [Fe(Dca $\left.)_{3}\right]$ and [TPrA] $\left[\mathrm{Co}(\mathrm{Dca})_{3}\right.$. The double adiabatic echo pulse sequence ${ }^{18}$ was employed to record the MAS NMR spectra and used square $\pi / 2$ excitation pulses of duration $1.25 \mu \mathrm{s}$ and rotor synchronised short (50 $\mu \mathrm{s})$ high powered adiabatic tanh/tan (SHAPs) ${ }^{18}$ inversion pulses sweeping through $10 \mathrm{MHz}$ to refocus the chemical shift evolution ${ }^{18}$; this sequence shows an approximate two-fold increase in signal intensity versus the double echo pulse sequence employing square $\pi / 2$ and $\pi$ pulses, largely in agreement with the literature ${ }^{18}$. TEDOR experiments ${ }^{18,20}$ were performed with an optimised recoupling time equal to 3 rotor periods (50 $\mu \mathrm{s})$ and adiabatic SHAPs inversion pulses applied to the ${ }^{1} \mathrm{H}$ channel to improve polarization transfer ${ }^{18}$. TEDOR experiments were performed with a recycle delay of $1.3 \times{ }^{1} \mathrm{H} \mathrm{T}_{1}$ to ensure maximum signal to noise per unit time. No ${ }^{1} \mathrm{H}$ decoupling was used during any ${ }^{13} \mathrm{C}$ acquisition. The ${ }^{13} \mathrm{C}$ MAS NMR spectra were typically accumulated with 2 million scans with recycle delays of $0.01 \mathrm{~s}$ which were found to be long enough to avoid saturation. Note that the ${ }^{13} \mathrm{C}$ signal intensities do not directly relate to the number of carbons present as the optimised data acquisition strategy is not quantitative due to the likely large differences in the ${ }^{13} \mathrm{C} \mathrm{T}_{2}$ ' values. ${ }^{1} \mathrm{H}$ spectra were referenced to $\mathrm{H}_{2} \mathrm{O}$ at $4.8 \mathrm{ppm}$ and ${ }^{13} \mathrm{C}$ spectra were reference to the $\mathrm{CH}$ peak of adamantane at $29.45 \mathrm{ppm}$ corresponding to TMS at $0 \mathrm{ppm}^{51}$. All samples for NMR were finely ground.

\section{FT-IR study}

Fourier-transform Infrared spectra were collected in Transmittance mode using a Bruker Tensor 27 spectrometer on grounded crystal, prior to melting and glass samples.

\section{Diffuse reflectance UV-Vis study}

A Perkin Elmer Lambda 750 spectrophotometer was used to measure the solid-state diffuse reflectance UV-Vis spectra. Spectra for all grounded crystalline and glass 
powder samples were recorded in the range of $200-800 \mathrm{~nm}$. A BaSO 4 matrix was used as a reference.

\section{Magnetic study}

A SQUID MPMS 3 instrument was used to conduct the magnetic measurements of hybrid perovskite crystals and glasses. The temperature variation of field-cooled susceptibility $(M-T)$ data was collected at 500 Oe magnetic field at a temperature range $2-300 \mathrm{~K}$. Magnetization as a function of magnetic field $(M-H)$ was measured at temperature $300 \mathrm{~K}$, with magnetic field varying up to $7 \mathrm{~T}$. Samples were placed in a light weight homogeneous quartz tube to minimize the background noise and stray field effects. The magnetic data were corrected for the diamagnetic contribution from the quartz sample holder and the intrinsic diamagnetism of the samples by the standard literature using Pascal's constants ${ }^{52}$.

\section{X-ray total scattering experiments}

Total X-ray scattering experiments were performed at ISIS facility, Oxford, UK using a Ag X-ray source. Samples of all three states of hybrid perovskites, crystal, recovered crystal heated just below melting and recovered glass were loaded into silica glass capillaries of $1 \mathrm{~mm}$ (inner) diameter. Data from the samples, empty instrument and empty capillary were collected in the region of $\sim 0.6<Q<\sim 17 \AA^{-1}$. Corrections for multiple scattering, background, container scattering, Compton scattering and absorption were performed using the GudrunX programme.

\section{First-principles molecular dynamics}

The behaviour of the system as a function of temperature was studied by means of density functional theory (DFT)-based molecular dynamics (MD) simulations, using the Quickstep module ${ }^{53}$ of the CP2K software package (Available online at http://www.cp2k.org). We used the hybrid Gaussian and plane wave method GPW53 as implemented in CP2K. The simulations were performed in the constant-volume ( $N$, $V, T$ ) ensemble with fixed size and shape of the unit cell. A time step of $0.5 \mathrm{fs}$ was used in the MD runs, and the temperature was controlled by velocity rescaling ${ }^{54}$. The exchange-correlation energy was evaluated in the PBE approximation ${ }^{55}$ and the dispersion interactions were treated at the DFT-D3 level ${ }^{56}$. The Quickstep module uses a multigrid system to map the basis functions onto. We kept the default number of 4 different grids, chose a plane-wave cutoff for the electronic density of $600 \mathrm{Ry}$, and a relative cutoff of $40 \mathrm{Ry}$. Valence electrons were described by double- $\zeta$ valence polarized basis sets and norm-conserving Goedecker-Teter-Hutter ${ }^{57}$ pseudopotentials all adapted for PBE (DZVP-GTH-PBE) for $\mathrm{H}, \mathrm{C}$ and $\mathrm{N}$ or optimized for solids (DZV-GTH-PADE) in the case of Mn.

Data availability: The unit cell studied was the tetragonal crystallographic unit cell, which contains 456 atoms, with cell parameters $a=b=16.275 \AA, c=17.423 \AA$, and $\alpha$ $=\beta=\gamma=90^{\circ}$. Representative input files for the molecular dynamics simulations are 
available as Supporting Information and online in our data repository at https://github.com/fxcoudert/citable-data.

\section{Network density measurements}

Physical densities of all hybrid perovskite crystals and glasses were measured using Micromeritics Accupyc 1340 helium pycnometer. The typical mass used for each test was around $80 \mathrm{mg}$. The reported values were averaged over a cycle of 10 measurements.

\section{Nanoindentation experiments}

Dense flat pieces of quenched-glass samples were mounted with epoxy resin and finely polished prior to Nanoindentation tests. A MTS Nanoindenter XP instrument was used under dynamic displacement controlled mode, at a constant strain rate of 0.05 $\mathrm{s}^{-1}$ at ambient conditions. Deformation of the polished samples was made using a Berkovich diamond tip, pre-calibrated with fused silica. A Poisson's ratio of $v=0.2$ was used in accordance with prior literature ${ }^{45}$. Absolute values of Young's modulus $(E)$ were determined from the variable indentation depth scans to a maximum surface penetration of $1000 \mathrm{~nm}$ which are shown with error bars over 20 consecutive scans.

\section{AC electrical conductivity measurements}

Room temperature AC conductivity measurements were performed with an Agilent E4980A Precision LCR meter, capable to measure in the frequency range from $20 \mathrm{~Hz}$ up to $2 \mathrm{MHz}$. The values of DC-resistance were extracted from the Cole-Cole plot of Impedance spectra. Complex dielectric permittivity $\left(\varepsilon_{r}=\varepsilon_{r}^{\prime}-i \varepsilon_{r}^{\prime \prime}\right)$ were evaluated from the electric modulus spectra. To perform the measurements, glass samples were ground and pressed in the form of a pellet using hydraulic press with an applied force of 2 Tons. Highly conducting gold was sputtered to make the electrical contacts homogeneous (sample dimension: electrode surface area $\sim 0.125 \mathrm{~cm}^{2}$, thickness 0.09 $\mathrm{cm}$ for $a_{\mathrm{g}}[\mathrm{TPrA}]\left[\mathrm{Mn}(\mathrm{Dca})_{3}\right], \quad 0.06 \mathrm{~cm}$ for $a_{\mathrm{g}}[\operatorname{TPrA}]\left[\mathrm{Fe}(\mathrm{Dca})_{3}\right], \quad 0.07 \mathrm{~cm}$ for $\left.a_{\mathrm{g}}[\operatorname{TPrA}]\left[\mathrm{Co}(\mathrm{Dca})_{3}\right]\right)$. The data were collected in a nitrogen atmosphere where continuous vacuum and nitrogen gas were cycled to make the sample environment moisture free.

\section{Thermal conductivity measurements}

Thermal conductivities of the glasses were measured by Quantum Design's Physical Property Measurement System (DynaCool ${ }^{\mathrm{TM}}$ ) using the TTO mode (thermal transport option) in a two-probe lead configuration (Supplementary Fig. 32). The data were recorded with temperature ranging from 2 to $300 \mathrm{~K}$ in a static mode. To perform the measurements, ground glass samples were pressed in the form of a pellet using hydraulic press with an applied force of 2 Tons (sample dimensions: diameter $0.5 \mathrm{~cm}$; thickness $0.03 \mathrm{~cm}$ for $a_{\mathrm{g}}[\operatorname{TPrA}]\left[\mathrm{Mn}(\mathrm{Dca})_{3}\right], 0.05 \mathrm{~cm}$ for $a_{\mathrm{g}}[\operatorname{TPrA}]\left[\mathrm{Fe}(\mathrm{Dca})_{3}\right], 0.1 \mathrm{~cm}$ for $a_{g}[\operatorname{TPrA}]\left[\mathrm{Co}(\mathrm{Dca})_{3}\right]$ ) and sandwiched between two thermally and electrically conducting disk-shaped copper leads. Good contact ensured through the use of highly 
conducting silver epoxy adhesive (well cured at $50{ }^{\circ} \mathrm{C}$ for 2 hours). The copper leads were then mounted to the puck (sample holder) very carefully. The system is designed with a copper isothermal radiation shield, which screwed into the base of the puck to minimize radiation between the sample and the environment. A copper shield plate was also placed between the sample stage and the PC board sockets to minimize radiation effects. The emissivity of the glasses was considered as unity (the emissivity is not critical because the radiation heat transfer from the sample is negligible). After achieving the isothermal conditions in the sample, a constant current pulse was passed through the heating element and the temperature of the element was recorded simultaneously by recording its voltage change. The TTO system measures thermal conductivity $\kappa$ by applying heat from the heater shoe in order to create a specified temperature differential $(\Delta \mathrm{T})$ between the two thermometer shoes. It dynamically models the thermal response of the sample to the low-frequency, square-wave heat pulse, and expediting data acquisition.

\section{Elemental characterization from $\mathrm{CHN}$ analysis}

The elemental compositions were obtained from CHN analyzer (Supplementary Table 4). Compared to crystalline states, a minor decrease in the concentration of carbon $(\sim 0.4 \%)$ and nitrogen $(\sim 0.3 \%)$ was observed in the glasses. Ground powder samples were used to perform the measurements using CE440 Elemental Analyzer, EAI Exeter Analytical Inc.

\section{Elemental characterization from XPS spectroscopy}

The peak fitting of the relative counts of $x$-ray photoelectron spectra (Supplementary Fig. 33) reveals unchanged composition from crystals to glasses (Supplementary Fig. 34, 35, 36; Supplementary Table 4). A tiny O1s peak at $530 \mathrm{eV}$ appeared in the glass phases reveals a minor oxidation taken place upon vitrification (Supplementary Fig. 33). Ground powder samples of crystals and glasses were used to perform the measurements using Escalab 250Xi, monochromatic Al k Alpha x-ray source. An inert, UHV conditions were also applied.

\section{Elemental characterization from SEM-EDX analysis}

The percentage of $\mathrm{N}$ and $\mathrm{M}$ contents was evaluated for the glasses from SEM-EDX spectra (Supplementary Fig. 37, Supplementary Table 4). Nitrogen ratios were found to vary slightly in comparison to the XPS and $\mathrm{CHN}$ results. The spectra were recorded with a high energy electron beam $\sim 10 \mathrm{keV}$. 